\title{
Targeting Gastrointestinal Transport Proteins to Control Hyperphosphatemia in Chronic Kidney Disease
}

\author{
Denis Fouque $^{1} \cdot$ Marc Vervloet $^{2} \cdot$ Markus Ketteler $^{3}$
}

Published online: 18 July 2018

(c) The Author(s) 2018

\begin{abstract}
Management of hyperphosphatemia in patients with dialysis-dependent chronic kidney disease remains a major challenge, requiring a multifaceted approach that includes dietary phosphate restriction, dialysis, and phosphate binders. However, these treatments fail to meet serum phosphate targets in many patients, potentially further exacerbating the significant morbidity and mortality burden associated with the disease. Recent advances in our understanding of the mechanisms underlying phosphate homeostasis have shed new light on the issue and suggest that gastrointestinal transport proteins may be promising targets for new hyperphosphatemia treatments. Drugs that inhibit or downregulate these transport proteins, and thus reduce phosphate uptake from the gut, may overcome some of the limitations of existing phosphate-lowering strategies, such as interdialytic rises in serum phosphate levels, poor adherence to dietary and phosphate-binder regimens, and maladaptive responses that can increase gastrointestinal phosphate absorption. Here, we review the latest preclinical and clinical data for two candidates in this novel drug class: tenapanor, a small-molecule inhibitor of the sodium/hydrogen ion-exchanger isoform 3 , and nicotinamide, an inhibitor of sodium-phosphate- $2 b$ cotransporters. We also discuss how potential synergies in their mechanisms of action suggest that coadministering phosphate binders with sodium-phosphate-2b cotransporter inhibitors may yield additive benefits over traditional phosphate-binder therapy.
\end{abstract}

Markus Ketteler

markus.ketteler@ regiomed-kliniken.de

1 Department of Nephrology, Centre Hospitalier Lyon-Sud, Université de Lyon, Carmen, 165 Chemin du Grand Revoyet, 69495 Pierre-Bénite, France

2 Department of Nephrology and Amsterdam Cardiovascular Sciences (ACS), VU University Medical Center, De Boelelaan 1117, $1081 \mathrm{HV}$ Amsterdam, Netherlands

3 Division of Nephrology, Klinikum Coburg GmbH, Ketschendorfer Str. 33, D-96450 Coburg, Germany

\section{Key Points}

Hyperphosphatemia is a significant problem in patients with chronic kidney disease, with high serum phosphate levels associated with increased mortality.

Many patients cannot adequately maintain serum phosphate concentrations at recommended levels despite current treatments such as dietary phosphate restriction, dialysis, phosphate binders, and controlling secondary hyperparathyroidism.

Tenapanor and nicotinamide are two promising new treatments for hyperphosphatemia; by inhibiting active gastrointestinal phosphate absorption, these treatments may prove to be useful alternative or additional therapies for hyperphosphatemia in chronic kidney disease. 


\section{Introduction}

In chronic kidney disease (CKD), glomerular filtration rate (GFR) declines, and phosphate excretion becomes increasingly dependent on the actions of fibroblast growth factor 23 (FGF-23) and parathyroid hormone (PTH); both inhibit tubular phosphate reabsorption in order to maintain phosphate homeostasis. However, these mechanisms cannot compensate for continual decline in GFR, and hyperphosphatemia develops. This can be further exacerbated by dietary phosphate load, the major contributor to the body's exchangeable pool of phosphate, and by CKD-related bone disease, where bone is resorbed more rapidly than it is formed or where its phosphate absorbing capacity is compromised (Fig. 1) [1,2]. Here, we review active phosphate transport mechanisms and their potential role as targets for novel hyperphosphatemia treatment strategies in CKD.

\section{Overview of Phosphate Transport and Homeostasis}

Under normal conditions, serum phosphate levels are governed by gastrointestinal absorption/secretion, bone formation/resorption, and renal reabsorption/excretion $[1,3]$. In healthy adults, dietary phosphate is absorbed via the intestines into an exchangeable pool, comprising intracellular phosphate $(70 \%)$, bone $(29 \%)$, and serum phosphate $(<1 \%)$, with the proportion of phosphate absorption dependent on the ingested phosphate source. Phosphate exits the body predominantly via excretion of phosphate from the kidneys (Fig. 1) [1-3].

Historical views of mineral homeostasis regard the kidneys as the primary organ responsible for dealing with excess phosphate. Because intestinal dietary phosphate absorption was believed to occur by passive diffusion, the intestines were considered of secondary importance. It is now known that intestinal phosphate absorption occurs via two distinct mechanisms: passive paracellular transport

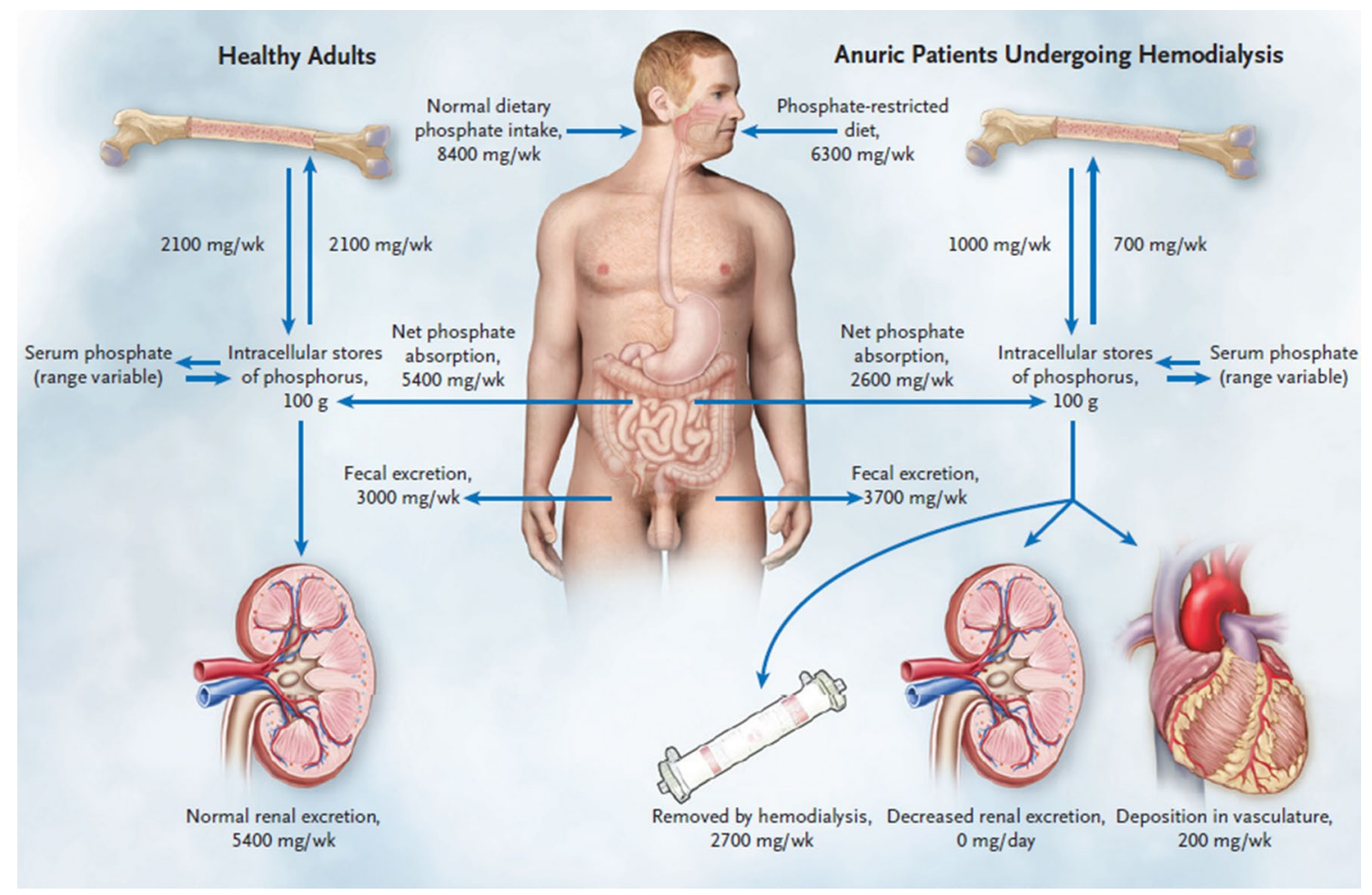

Fig. 1 Mechanisms underlying phosphate homeostasis in healthy adults and in patients with chronic kidney disease [2]. In healthy adults, phosphate intake is matched by phosphate excretion in feces and urine, and the flux of phosphate between the skeleton and the extracellular phosphate pool is approximately the same in both directions. In patients with chronic kidney disease, dietary restriction of phosphate is insufficient to compensate for the decrease in renal phosphate excretion, resulting in a positive phosphate balance. In addi- tion, bone is often resorbed more rapidly than it is formed because of abnormal bone remodeling in kidney failure. Together, these abnormalities may confer a predisposition to vascular calcification, especially when serum phosphate levels are suboptimally controlled. The phosphate values shown are for illustrative purposes only, as these values vary from patient to patient. Reproduced with permission from Tonelli et al. [2] 
along concentration gradients, and active sodium-dependent transcellular transport via carrier or transporter proteins. Expression of these gastrointestinal transporters is increased by active vitamin $\mathrm{D}$ [4].

A study in patients with CKD showed that the balance between the two mechanisms was affected by vitamin D levels and dietary phosphate intake [5]. Vitamin D deficiency reduced the rate of active phosphate absorption but did not affect passive absorption. Phosphate transport was also affected by luminal phosphate concentration, with absorption dependent on active transport at low concentrations and passive transport predominating at high concentrations; this is commonly the case with Western diets [5].

In passive paracellular transport, substrate movement occurs along a concentration gradient through tight junction complexes formed between adjacent cells [3]. Tight junction complexes function as a selective barrier to restrict paracellular diffusion, and are formed by interactions between complementary adhesive transmembrane proteins, such as occludin and claudins, located in the lateral cell membrane. These complexes interact with the cytoskeleton and signal transduction pathways, and differ in their morphology and permeability characteristics across different tissues. Evidence suggests that occludin and claudins are important for ion specificity. However, specific tight junction proteins associated with phosphate specificity have yet to be identified [3].

Two families of solute carrier (SLC) membrane proteins mediate sodium (Na)-dependent cotransport of inorganic phosphate $(\mathrm{Pi})$ across cell membranes-SLC34 and SLC20 [4, 6]. In the SLC34 cotransporter family, NaPi2b (SLC34A2) is primarily responsible for phosphate absorption in the gut, and the main function of NaPi2a (SLC34A1) and NaPi2c (SLC34A3) is mediation of transcellular phosphate reabsorption in the renal proximal tubule (Fig. 2) [4, 6]. The SLC20 cotransporters, PiT-1 (SLC20A1) and PiT-2 (SLC20A2), are expressed ubiquitously and were considered historically to be "housekeeping" transport proteins [6]. However, PiT-1 is now believed to play a role in intestinal phosphate absorption [4, 7], and PiT-2, which is present in rat renal proximal tubule brush-border membranes [4], is downregulated following administration of a high (1.2\%) phosphate-containing diet, suggesting a regulatory role for this transporter on an organism level [8].

Animal data support the notion that renal mechanisms are not the sole effectors of phosphate homeostasis, with evidence suggesting that intestinal NaPi2b cotransporters play a significant role [4]. Studies in adult conditional $\mathrm{NaPi} 2 \mathrm{~b}$-knockout mice demonstrated that intestinal $\mathrm{NaPi} 2 \mathrm{~b}$ cotransporters make up $>90 \%$ of active phosphate absorption, contributing up to $50 \%$ of total phosphorus uptake. Interestingly, the decreased phosphate absorption in this model was countered by a compensatory decrease in urinary
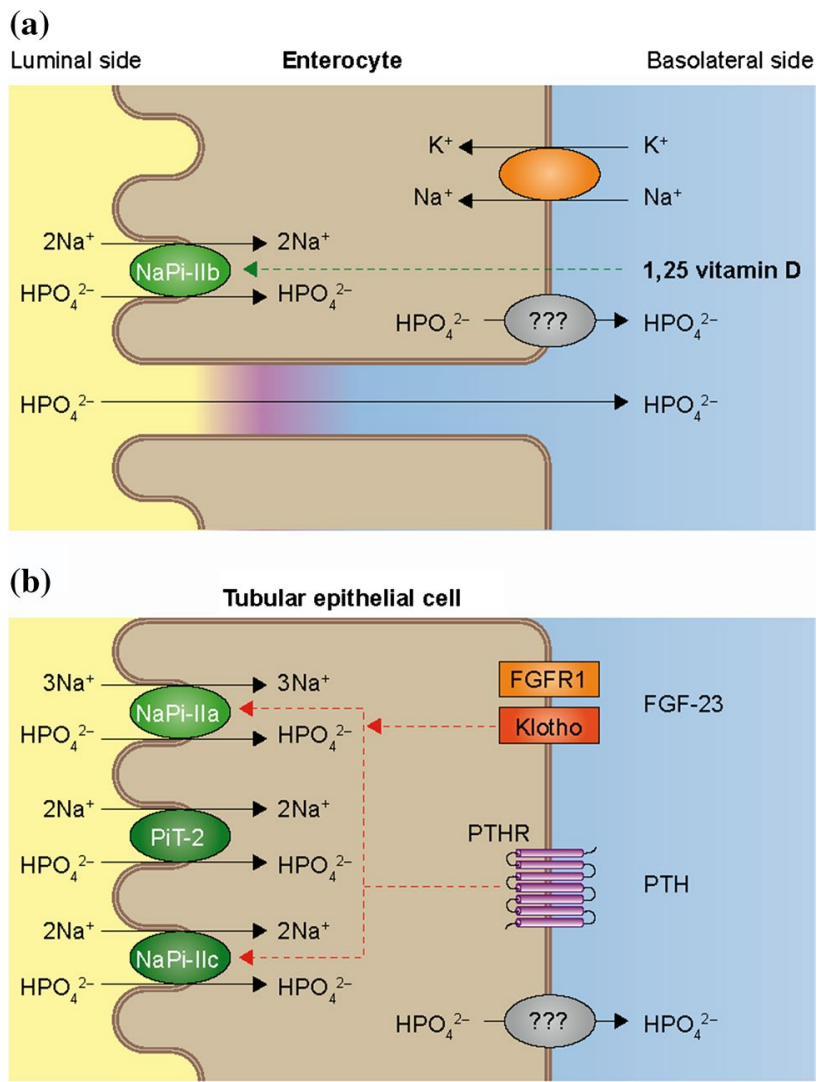

Fig. 2 Role of NaPiII family of sodium-phosphate cotransporters in the intestines and in the kidney [120]. a Intestinal phosphate uptake occurs by active transport via sodium-phosphate cotransporters (NaPi-IIb) and is positively regulated (dotted green arrow) by active vitamin D. Phosphate is subsequently transported into the circulation by an as yet unknown mechanism (represented in the figure as '???'). Electrogenic balance is accounted for by the sodium-potassium exchanger in the basolateral membrane. Additionally, passive phosphate transport takes place through a paracellular pathway, which is diffusion-driven and is mostly regulated by dietary phosphate intake. b In the kidney, an active transport process takes place that is highly similar to that seen in the intestine. Upon free glomerular filtration, phosphate is reabsorbed by NaPi-IIa and NaPi-IIc transporters, with PiT-2 transporters also contributing to this process. Phosphate is subsequently transported back into the circulation. NaPi-IIa and NaPiIIc are negatively regulated by PTH and FGF-23, either directly or by enhancing the effect of PTH (dotted red arrow). Reproduced with permission from Baia et al. [120]. 1,25 vitamin D 1,25 dihydroxyvitamin $\mathrm{D}_{3}, F G F-23$ fibroblast growth factor $23, F G F R 1$ fibroblast growth factor receptor 1, PTH parathyroid hormone, PTHR parathyroid hormone receptor

phosphate excretion, mediated by renal NaPi2a upregulation [9]. In the context of an experimental CKD model, where compensatory renal phosphate excretion is lost, mice lacking the $\mathrm{NaPi} 2 \mathrm{~b}$ cotransporter have significantly lower serum phosphate levels than their wildtype counterparts $(8.21 \pm 0.56$ vs. $10.04 \pm 0.51 \mathrm{mg} / \mathrm{dL} ; p<0.05)[10]$.

Dietary and pharmacological phosphate restriction influences intestinal $\mathrm{NaPi} 2 \mathrm{~b}$ expression across species. Adaptive 
increases in intestinal $\mathrm{NaPi}$ transport activity and $\mathrm{NaPi} 2 \mathrm{~b}$ expression have been observed in rats, mice, goats, and pigs in response to chronic dietary phosphate restriction, conceivably in an attempt to maintain phosphate uptake [7, 9, 11-14]. From an evolutionary perspective, this makes sense in order to save the body from inappropriate phosphate deprivation. Importantly, although vitamin D deficiency in CKD may limit gastrointestinal NaPi2b expression, studies in mice have demonstrated that even in the complete absence of active vitamin D or its receptor, dietary phosphate restriction upregulates $\mathrm{NaPi} 2 \mathrm{~b}[15,16]$.

In mice, switching abruptly from a low- to a high-phosphate diet can lead to a maladaptive increase in intestinal $\mathrm{NaPi}$ transport activity, inducing transient postprandial hyperphosphatemia [3, 7]. Postprandial hyperphosphatemia also occurs in humans $[3,17,18]$. Phosphate-binder treatment, which essentially mimics the effects of a low-phosphate diet, also enhances intestinal $\mathrm{NaPi} 2 \mathrm{~b}$ expression in mice [10]. Injecting FGF-23 into normal mice has been shown to lower levels of 1,25-dihydroxyvitamin $\mathrm{D}_{3}$ and serum phosphate [19]. FGF-23 also has been shown to inhibit intestinal $\mathrm{NaPi}$ transport activity and reduce $\mathrm{NaPi} 2 \mathrm{~b}$ protein in brush-border membranes in a vitamin $\mathrm{D}$ receptordependent manner [19]. Finally, 1,25-dihydroxyvitamin $\mathrm{D}_{3}$ can enhance intestinal $\mathrm{NaPi} 2 \mathrm{~b}$ expression in wildtype mice and rats $[12,20]$; this is important because many patients with CKD are prescribed active vitamin D metabolites.

Humans with an NaPi2b loss-of-function mutation do not develop hypophosphatemia [21,22], likely owing to increased renal $\mathrm{NaPi} 2 \mathrm{a}$ expression. Preclinical data indicate that nearly half of intestinal phosphate transport is NaPi2bmediated [9]. However, this proportion may be smaller in patients with CKD owing to low vitamin D levels, in part a consequence of increased vitamin D catabolism driven by high concentrations of FGF-23 [2]. Alternatively, considering that $\mathrm{NaPi} 2 \mathrm{~b}$ cotransporters may be upregulated by therapy directed at improving mineral and bone disease in CKD (low-phosphate diet, phosphate binders, vitamin D supplementation) and the postprandial increase in intestinal $\mathrm{NaPi}$ activity $[3,10], \mathrm{NaPi} 2 \mathrm{~b}$ is a potential target for hyperphosphatemia therapies.

\section{Epidemiology and Impact of Hyperphosphatemia in Chronic Kidney Disease}

The prevalence of hyperphosphatemia in patients with CKD increases with decreasing kidney function [23-25]. However, following a subtle decline in serum phosphate levels during the earliest stages of CKD, increased serum phosphate levels occur once CKD has progressed [25], suggesting phosphate homeostatic compensatory mechanisms may remain effective up to CKD stage 3.

A link between hyperphosphatemia and mortality was first shown in 1998 [26], but strong evidence demonstrating its independent association with increased morbidity and mortality was not available until 2004 [27]. In a large, retrospective analysis of data from 40,538 US patients with CKD receiving hemodialysis, serum phosphate concentrations $>5.0 \mathrm{mg} / \mathrm{dL}$ were found to be associated with a significantly elevated relative risk of mortality $(p<0.05)$, which rose incrementally with each additional $1.0 \mathrm{mg} / \mathrm{dL}$ increase in phosphate level [27]. The highest category of serum phosphate concentration $(\geq 11.0 \mathrm{mg} / \mathrm{dL})$ was associated with the greatest increase in relative risk of mortality (2.47; 95\% confidence interval [CI] 1.90-3.19); hyperphosphatemia was also significantly $(p<0.05)$ associated with all-cause, cardiovascular, and fracture-related hospitalization [27]. A more robust methodological approach accounting for time-dependent variations in clinical and laboratory measures was adopted in a large historical cohort analysis of patients receiving maintenance hemodialysis $(n=58,058)$ [28]. Regardless of the model used, hyperphosphatemia was found to be strongly and independently associated with mortality, supporting a causal role for phosphate [28].

Many observational studies subsequently confirmed this association between hyperphosphatemia and increased risk of mortality, but by their design all these studies precluded definite establishment of causality [29-33]. While no randomized controlled trials to date have demonstrated that reducing serum phosphate concentrations reduces mortality [34], a 3-year study of 1744 patients receiving dialysis identified that having serum phosphate levels above the normal range was associated with a significantly higher risk of death [35]. Additional support for the presumed causal role of hyperphosphatemia in poor outcomes comes from COSMOS (Current Management of Secondary Hyperparathyroidism: a Multicenter Observational Study), a 3-year, European, multicenter, open-cohort, observational study designed specifically to prospectively assess possible links between serum phosphate, calcium, PTH levels, and mortality risk in adults undergoing maintenance hemodialysis $(n=6307)$ [36]. In the study, both high and low serum phosphate levels were associated with increased mortality risk [36]. A serum phosphate concentration of $4.4 \mathrm{mg} / \mathrm{dL}$ was associated with the minimum relative risk for mortality, and the range in which patients faced the lowest mortality risk was $3.6-5.2 \mathrm{mg} /$ $\mathrm{dL}$ [36]. For patients whose baseline serum phosphate level was greater than $5.2 \mathrm{mg} / \mathrm{dL}$, reductions toward this range were associated with reduced mortality risk [36]. Further evidence comes from a 6-month observational study conducted in the USA in patients initiating hemodialysis $(n=102,754)$. This study showed that, compared 
with the reference range ( 3.5 to $<5.5 \mathrm{mg} / \mathrm{dL}$ ), higher and lower serum phosphate concentrations were associated with increased risk of all-cause mortality among patients whose serum concentrations did not change during hemodialysis [37]. For patients with phosphate levels above the reference range at baseline, increases in phosphate levels during hemodialysis were associated with an increased risk of mortality. For patients with the highest baseline phosphate levels $(\geq 7.5 \mathrm{mg} / \mathrm{dL})$, a reduction in phosphate levels $(\geq 0.5 \mathrm{mg} / \mathrm{dL})$ was associated with a decreased risk of mortality [37].

These data suggest a causal link between hyperphosphatemia and increased mortality. The improvements in survival observed when serum abnormalities were close to the lowest risk ranges support the rationale for controlling this parameter in patients with advanced CKD [35, 36]. However, whether this approach improves other clinical outcomes remains unproven. In addition to increased mortality risk, hyperphosphatemia is associated with a number of intermediate cardiovascular outcomes, such as increased arterial stiffness [38], coronary atherosclerosis [39], and vascular calcification [40], which may induce additional morbidity and negatively affect quality of life.

\section{Target Serum Phosphate Levels}

Several international foundations aim to develop evidencebased clinical practice guidelines for the management of patients with CKD. These include the Kidney Disease Outcomes Quality Initiative and the Kidney Disease: Improving Global Outcomes (KDIGO) Work Groups, both of which have published recommendations for serum phosphate targets; the KDIGO recommendations were updated in early 2017 (Table 1) [41, 42]. Most recent guidelines suggest lowering serum phosphate concentrations toward the normal range. However, attainment of these targets remains poor with current strategies [35, 43-49].

\section{Current Phosphate-Lowering Strategies}

The main strategies for managing hyperphosphatemia are optimizing dialysis schedules, dietary phosphate restriction, administering phosphate-binding agents, and controlling hyperparathyroidism [50]. Detailed discussions of the current recommendations for these approaches have been published elsewhere $[41,42,51,52]$, but the key limitations of these approaches are summarized in Table 2.

Dietary phosphate restriction is routinely recommended to reduce serum phosphate levels in patients with CKD, although achieving adequate phosphate restriction can prove challenging given the high phosphate content of Western diets $[50,53]$. Furthermore, marked restrictions in dietary phosphate can result in protein malnutrition. To date, no randomized controlled clinical trials have evaluated the effects of dietary phosphate restriction on clinical outcomes in patients on dialysis. Evidence from a 3-year observational cohort study in 30,075 patients on maintenance hemodialysis suggested that the risks of controlling serum phosphate levels through dietary protein restriction may outweigh its benefits [54]. This study showed that an increase in normalized protein nitrogen appearance (nPNA), a surrogate for dietary protein intake, together with a decrease in serum phosphate levels was associated with a reduced risk of mortality compared with an increase in both nPNA and serum phosphate levels. By contrast, a decrease in nPNA was associated with an increased mortality risk irrespective of whether serum phosphate levels increased or decreased [54].

Phosphate binders have a well-established efficacy profile in terms of reducing serum phosphate concentrations, but to date no randomized, double-blind,

Table 1 Overview of Kidney Disease: Improving Global Outcomes (KDIGO) guidelines for target serum phosphate levels in patients with chronic kidney disease

\begin{tabular}{ll}
\hline Guideline & Target serum phosphate level recommendation \\
\hline 2009 CKD-MBD clinical practice guideline document [41] & CKD stages 3-5 \\
& $\begin{array}{l}\text { Should be maintained within the normal range of 2.5-4.5 mg/dL } \\
\text { CKD stage 5D/patients on dialysis }\end{array}$ \\
& $\begin{array}{l}\text { Should be reduced toward the normal range of } 2.5-4.5 \mathrm{mg} / \mathrm{dL} \\
\text { CKD stages } 3 A-5 D\end{array}$ \\
2017 Clinical practice guideline update on diagnosis, evaluation, pre- & $\begin{array}{l}\text { Treatment of CKD-MBD should be based on serial assessments of } \\
\text { vention, and treatment of CKD-MBD [42] }\end{array}$ \\
& $\begin{array}{l}\text { phosphate, calcium, and PTH levels, considered together. Serum } \\
\text { phosphate levels should be reduced toward the normal range of } \\
2.5-4.5 \mathrm{mg} / \mathrm{dL}\end{array}$ \\
\hline
\end{tabular}

Conversion factors for units: serum phosphate in $\mathrm{mg} / \mathrm{dL}$ to $\mathrm{mmol} / \mathrm{L}, \times 0.3229$

$C K D$ chronic kidney disease, $C K D-M B D$ chronic kidney disease-mineral and bone disorder, $P T H$ parathyroid hormone 
Table 2 Overview of current strategies to lower serum phosphate levels and potential drawbacks of each intervention

\begin{tabular}{|c|c|}
\hline Strategy & Potential drawbacks of intervention \\
\hline Dialysis & $\begin{array}{l}\text { Dialysis carries a significant healthcare resource burden and has a marked impact on patients' daily activities } \\
\text { Three-times-weekly hemodialysis can remove only about } 3 \text { days' worth of ingested phosphate, meaning a rela- } \\
\text { tively large amount must be handled by dietary phosphate binders instead [50] }\end{array}$ \\
\hline Dietary phosphate restriction & $\begin{array}{l}\text { Achieving adequate dietary phosphate restriction can prove challenging in clinical practice }[50,53] \\
\text { Western diets have a high phosphate content, and marked restrictions can result in protein insufficiency [50] } \\
\text { Patients often find they are unable to adhere to these regimens [53] } \\
\text { Dietary phosphate restriction can lead to compensatory upregulation of NaPi2b-dependent phosphate transport [7, } \\
9,11-14]\end{array}$ \\
\hline Phosphate binders & $\begin{array}{l}\text { Most effective when dietary phosphate intake is }<1000 \mathrm{mg} / \mathrm{day} \text {; when phosphate intake is } \geq 2000 \mathrm{mg} / \mathrm{day} \text {, effec- } \\
\text { tiveness is reduced, and hyperphosphatemia may persist [53] } \\
\text { Calcium overload is a serious potential consequence of calcium-based binder use [42]. Non-calcium-based bind- } \\
\text { ers can eliminate this risk, but may be associated with other adverse events, such as aluminum accumulation } \\
\text { toxicity [114]. They may also be less cost-effective than calcium-based binders [115] } \\
\text { High phosphate-binder doses are often required, which may lead to high tablet burdens and issues with gastroin- } \\
\text { testinal tolerability } \\
\text { Phosphate-binder treatment can lead to compensatory upregulation of NaPi2b-dependent phosphate transport [10] } \\
\text { High tablet burdens are associated with nonadherence to treatment [116, 117], which, in turn, is associated with } \\
\text { poor phosphate control [116,118,119] }\end{array}$ \\
\hline Controlling PTH levels & $\begin{array}{l}\text { Calcimimetics can only lower the amount of phosphate mobilized from bone, limiting their effect to an estimated } \\
3 \% \text { reduction in serum phosphate concentration for every } 10 \% \text { reduction in PTH level [66]. This intervention } \\
\text { is restricted to patients with additional hyperparathyroidism, who only make up about } 40 \% \text { of all patients with } \\
\text { CKD stage 5D (dialysis-dependent) }\end{array}$ \\
\hline
\end{tabular}

$C K D$ chronic kidney disease, $N a P i 2 b$ sodium-phosphate cotransporter $2 \mathrm{~b}, P T H$ parathyroid hormone

placebo-controlled study has assessed the effects of phosphate binders on hard clinical outcomes, such as mortality or cardiovascular events, in patients on dialysis. However, clinical outcomes were investigated in the observational COSMOS trial [36]. Of the 6297 patients in COSMOS, all-cause mortality and cardiovascular mortality were significantly lower in patients prescribed phosphate binders than in those who were not, with hazard ratios $(95 \%$ CIs) of $0.71(0.61-0.82 ; p<0.001)$ and $0.78(0.62-0.97$; $p=0.03$ ), respectively [55]. Moreover, treatment with phosphate binders was independently associated with improved mortality compared with no phosphate-binder treatment in a prospective cohort study of 10,044 incident patients receiving hemodialysis, even after matching of propensity score for receiving phosphate binders and adjusting for confounders including malnourishment, which may have existed in those not in need of phosphate binders [56]. A second prospective cohort study of patients receiving hemodialysis $(n=23,898)$ also showed that prescription of phosphate binders was associated with lower mortality, even after adjustments for nutritional indicators [57]. A randomized, controlled pilot study (TARGET [Two Phosphate Targets In End-Stage Renal Disease Trial]) showed that it was possible to achieve and maintain different target serum phosphate levels in the two groups of patients on dialysis by titrating phosphate binders [58]. Further studies are now required to determine the effect on clinical outcomes of targeting different serum phosphate concentrations in patients on dialysis.

The KDIGO 2017 guidelines mention the potential harm of calcium exposure in patients with CKD [42]. An open-label, randomized controlled trial of calcium-based versus non-calcium-based phosphate binders [59] and two meta-analyses $[60,61]$ reported lower all-cause mortality with non-calcium-based binders (sevelamer) than with calcium-based binders. However, it is not possible to ascribe this difference to a beneficial effect of non-calcium binders or to harm inflicted by calcium-based binders owing to the lack of a placebo control arm to assess all-cause mortality [60-62] and the significant heterogeneity of this outcome among the trials examined [60, 63]. Indeed, questions regarding the methodology of the key study [59] also limit the conclusions that can be drawn from these analyses [63].

A further limitation of current phosphate-binder treatments is that although they reduce serum phosphate levels, many patients who take them do not reach recommended targets. For example, although $86.4 \%$ of the patients included in the COSMOS study received phosphate-binder therapy, only $26.7 \%$ attained the KDIGO serum phosphate target range (3.0-4.5 mg/dL) [64]. Poor target attainment may be because of suboptimal adherence to phosphate binders, inappropriate timing of drug-taking or blood sampling, the release of phosphate from bone, or, as discussed earlier, the upregulation of $\mathrm{NaPi} 2 \mathrm{~b}$ in the gastrointestinal tract following 
phosphate binders or dietary phosphate restriction [7, 9-14]. Should these compensatory mechanisms occur in patients, they may reduce the efficacy of phosphate binders, and even exacerbate phosphate uptake if adherence is variable.

Controlling hyperparathyroidism is important because, when severe, it can aggravate hyperphosphatemia via increased mobilization of phosphate from bone [50]. Analyses have shown that treating hyperparathyroidism with the oral calcimimetic agent cinacalcet hydrochloride significantly reduced serum phosphate concentrations $[65,66]$. However, patients with secondary hyperparathyroidism represent only $40 \%$ (27.9-54.2\% globally) [67] of all adult dialysis-dependent patients.

Only a small proportion of patients reach target phosphate levels with dialysis, dietary phosphate restriction, phosphate binders, and calcimimetics. Considering this together with the known impact of elevated phosphate levels on cardiovascular risk and mortality, there remains an unmet need for further treatment options that can safely lower serum phosphate levels more effectively toward normal ranges.

\section{Alternative Treatment Strategies for Hyperphosphatemia: Targeting Gastrointestinal Transport}

To date, there are no approved treatments for hyperphosphatemia that specifically target the intestinal transepithelial transport of phosphate, although a number of treatments are currently in development. As mentioned earlier, intestinal phosphate absorption occurs by two distinct mechanisms (passive paracellular transport via tight junctions and active sodium-dependent transcellular transport via ion cotransporters). Two investigational compounds affect passive paracellular transport: tenapanor (RDX5791/AZD1722; Ardelyx, Inc., Fremont, CA, USA), a small-molecule inhibitor of the sodium/hydrogen ion-exchanger isoform 3 (NHE3), which has shown promising results in preliminary studies, and TP0469711, another NHE3 inhibitor that is in the early stages of development. In addition, two agents target active sodium-dependent transcellular transport, and represent an alternative mode of action. Nicotinamide, the amide form of vitamin $\mathrm{B}_{3}$, inhibits $\mathrm{NaPi}$ cotransporters, and preliminary studies have yielded promising results; ASP3325 inhibits $\mathrm{NaPi} 2 \mathrm{~b}$ and is at an earlier stage of development.

\subsection{Ion-Exchanger Inhibitors: Tenapanor and TP0469711}

Tenapanor is a small-molecule inhibitor of NHE3 that produces reductions in intestinal sodium and phosphate absorption $[68,69]$. It is under development for several indications, including hyperphosphatemia in patients with CKD receiving hemodialysis. In the intestine, tenapanor reduced absorption of phosphate with minimal systemic exposure (Table 3) [69-73]. Exactly how tenapanor reduces intestinal phosphate absorption is not well understood, and the underlying mechanisms are being investigated. However, it does not seem to involve direct inhibition of type 1 intestinal transport proteins or the $\mathrm{NaPi} 2 \mathrm{~b}$ cotransporter [68]. Evidence suggests that NHE3 inhibition by tenapanor temporarily increases the intracellular hydrogen ion concentration of epithelial cells, which reduces the permeability of tight junctions to phosphate, thereby reducing the paracellular absorption of luminal phosphate $[74,75]$. This is important because passive paracellular phosphate transport is thought to account for the majority of phosphate absorption in humans.

Results have been published from a phase II, randomized, double-blind, placebo-controlled, dose-finding study that assessed the effects of tenapanor on serum phosphate concentrations in patients receiving hemodialysis $(n=162)$ [76]. After a 1- to 3-week phosphate-binder washout period, patients with hyperphosphatemia (serum phosphate level $6.0-10.0 \mathrm{mg} / \mathrm{dL}$ and an increase of $1.5 \mathrm{mg} / \mathrm{dL}$ from screening) were randomized equally to receive tenapanor $2,3,6$, 20,30 , or $60 \mathrm{mg} /$ day or placebo for 4 weeks [76]. Tenapanor induced dose-dependent reductions in mean serum phosphate level from baseline, ranging from -0.47 to $-1.98 \mathrm{mg} /$ $\mathrm{dL}$ (vs. $-0.54 \mathrm{mg} / \mathrm{dL}$ with placebo; $p=0.01$ ), with the largest reductions occurring in the tenapanor 20 and $60 \mathrm{mg} /$ day groups (both $p<0.05$ vs. placebo) [76]. Tenapanor was generally well tolerated at the lowest dose ( $2 \mathrm{mg} /$ day), with a similar incidence of adverse events (AEs) to placebo (43 and $42 \%$, respectively). AEs were more frequent at higher tenapanor doses (57-76\%). The most common AEs were gastrointestinal-related, such as diarrhea (tenapanor, 26\% at $2 \mathrm{mg} /$ day, $18-68 \%$ at higher doses; placebo, $12 \%$ ) and nausea (tenapanor, no cases at $2 \mathrm{mg} / \mathrm{day}, 4-9 \%$ at higher doses; placebo, 4\%). The most common AE causing discontinuation was diarrhea (tenapanor, $9 \%$ at $2 \mathrm{mg} / \mathrm{day}, 0-32 \%$ at higher doses; no cases with placebo) [76]. Studies have identified the need to clarify the optimal dosing of tenapanor for patients with hyperphosphatemia $[72,76]$.

Another NHE3 inhibitor, TP0469711, is under investigation for the treatment of hyperphosphatemia. Early preclinical in vitro and rodent data have demonstrated its phosphatelowering potential [77].

\subsection{Sodium-Phosphate Cotransporter Inhibitors}

Given their apparent role in phosphate homeostasis [7, 9-14], targeting intestinal $\mathrm{NaPi} 2 \mathrm{~b}$ cotransporters is a logical step in the development of novel treatments for hyperphosphatemia. 


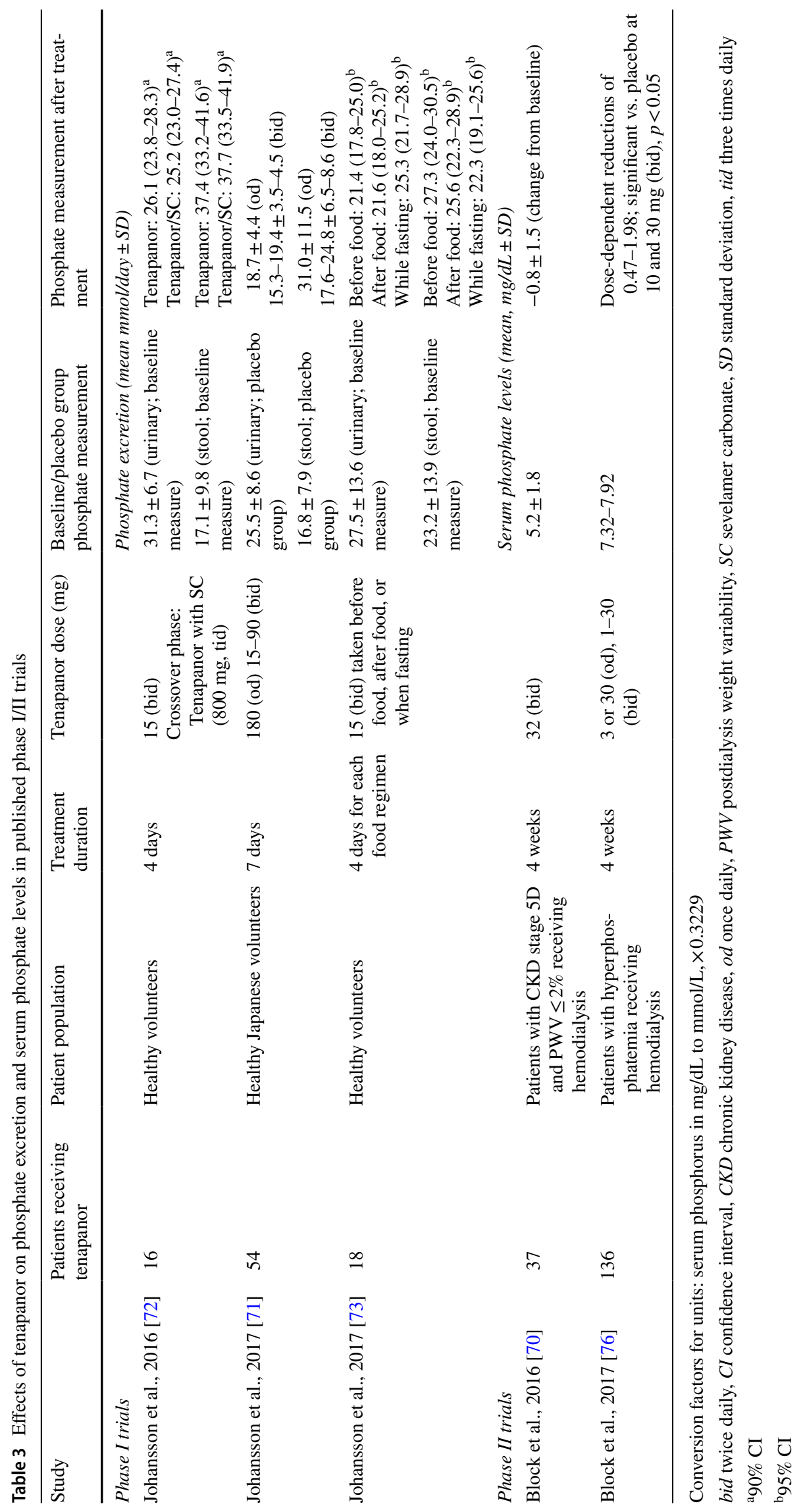


ASP3325 is an inhibitor of NaPi2b and has been shown to reduce NaPi2b-mediated phosphate uptake in vitro and reduce serum phosphate concentrations in a rat model of renal failure [78]. While ASP3325 was well tolerated in patients with end-stage renal disease in a phase Ia clinical trial, no effect was observed on serum phosphate concentrations [79].

Nicotinic acid (niacin) is a water-soluble organic compound with a pyridine ring and a molecular formula of $\mathrm{C}_{6} \mathrm{H}_{5} \mathrm{NO}_{2}$ with a carboxyl group at the 3-position, otherwise known as vitamin $B_{3}$. Nicotinic acid can be metabolized to nicotinamide (also known as niacinamide), the corresponding amide [80]. Both forms have demonstrated phosphatelowering activity [81-83].

While the exact mode of action remains unknown, animal studies have suggested that nicotinamide reduces hyperphosphatemia in an NaPi2b-dependent manner [9]. Nicotinamide lowered sodium-dependent intestinal phosphate absorption and reduced $\mathrm{NaPi} 2 \mathrm{~b}$ expression $[84,85]$, while the expression of Pit-1 and Pit-2 transporters remained unchanged [85]. In addition, nicotinamide administration has been shown to produce marked increases in renal phosphate excretion in animal studies, acting via inhibition of sodiumdependent renal phosphate transport [86-89]. Nicotinamide was associated with a reduction in $\mathrm{NaPi}$ a levels in renal cells in some in vitro models, which may also explain this observation [90].

\section{Nicotinamide}

\subsection{Proof-of-Concept Studies}

The potential to reduce hyperphosphatemia in humans with nicotinamide has been demonstrated in several small studies conducted in patients receiving dialysis (Table 4) [81, 91-96]. These include a 12-week, proof-of-concept study in patients on long-term hemodialysis $(n=65)$ in which nicotinamide monotherapy was administered at a starting dose of $500 \mathrm{mg} /$ day and was increased thereafter by $250 \mathrm{mg} /$ day every 2 weeks until phosphate control $(<6.0 \mathrm{mg} / \mathrm{dL})$ was achieved [81]. Rapid (from week 3), sustained (up to week 12 ), and significant reductions in mean serum phosphate levels were observed, decreasing from $6.9 \mathrm{mg} / \mathrm{dL}$ at baseline to $5.4 \mathrm{mg} / \mathrm{dL}$ during treatment $(p<0.001)$ [81]. Furthermore, mean serum phosphate increased significantly to $6.7 \mathrm{mg} / \mathrm{dL}$ following a 2 -week post-treatment washout period ( $p<0.001)$, suggesting that the phosphate-lowering effect was attributable to nicotinamide [81].

\subsection{Head-to-Head Comparator Studies}

In a 24-week, multicenter, randomized, open-label, noninferiority study in patients receiving long-term hemodialysis $(n=100)$, nicotinamide monotherapy $(0.5-2.0 \mathrm{~g} /$ day) appeared to be as effective as sevelamer (3.2-9.6 g/ day) [94]. After 24 weeks of treatment, reductions in serum phosphate from baseline were similar with nicotinamide $(6.50-5.57 \mathrm{mg} / \mathrm{dL})$ and with sevelamer $(7.12-5.26 \mathrm{mg} /$ dL) [94]. However, the non-inferiority criterion was not met, possibly because a smaller number of patients were included than planned [94]. The treatment discontinuation rate due to AEs was 1.6-fold higher with nicotinamide than with sevelamer, with $55 \%$ of patients in the nicotinamide group completing the entire treatment period compared with $90 \%$ in the sevelamer group. However, patients previously treated with sevelamer were not excluded from this study, implying a possible selection bias favoring tolerability with sevelamer. Notably, pill burden was much lower with nicotinamide (mean dose $1.3 \mathrm{~g} / \mathrm{day}$, equivalent to 2.6 tablets) than with sevelamer (mean dose $8.6 \mathrm{~g} /$ day, or 10.8 tablets). Another difference was that FGF23 concentrations declined in the sevelamer arm, while they increased in those allocated to nicotinamide [94].

\subsection{Add-On Studies}

Coadministration of $\mathrm{NaPi} 2 \mathrm{~b}$ cotransporter inhibitors and phosphate binders may show greater efficacy in reducing serum phosphate than phosphate-binder monotherapy, owing to the complementary mechanisms of action. Nicotinamide has the potential to overcome limitations of phosphate binders and dietary phosphate restriction by limiting the effect of any $\mathrm{NaPi} 2 \mathrm{~b}$ upregulation observed upon reducing intestinal phosphate concentrations, and combining nicotinamide with phosphate binders (and/or dietary phosphate restriction) may maximize reductions in intestinal phosphate absorption. The benefits of nicotinamide are that its administration is independent of food intake and that a modified-release formulation may permit once-daily dosing and simple treatment regimens. Additional potential benefits may include reduced phosphate-binder dose and pill burden, reduced dosedependent AEs, reduced calcification risk (should lower doses of calcium-based binders be needed when coadministered with nicotinamide), and optimized effects of dietary phosphate restriction, although these remain to be proven.

Results from two small studies appear to confirm that coadministering nicotinamide with phosphate binders yields greater reductions in serum phosphate concentration than phosphate-binder monotherapy $[92,93]$. In one study, children undergoing hemodialysis $(n=60)$ were randomized $1: 1$ to receive nicotinamide (100 $\mathrm{mg}$ two or three times daily) plus calcium-based phosphate binders, or calcium-based 


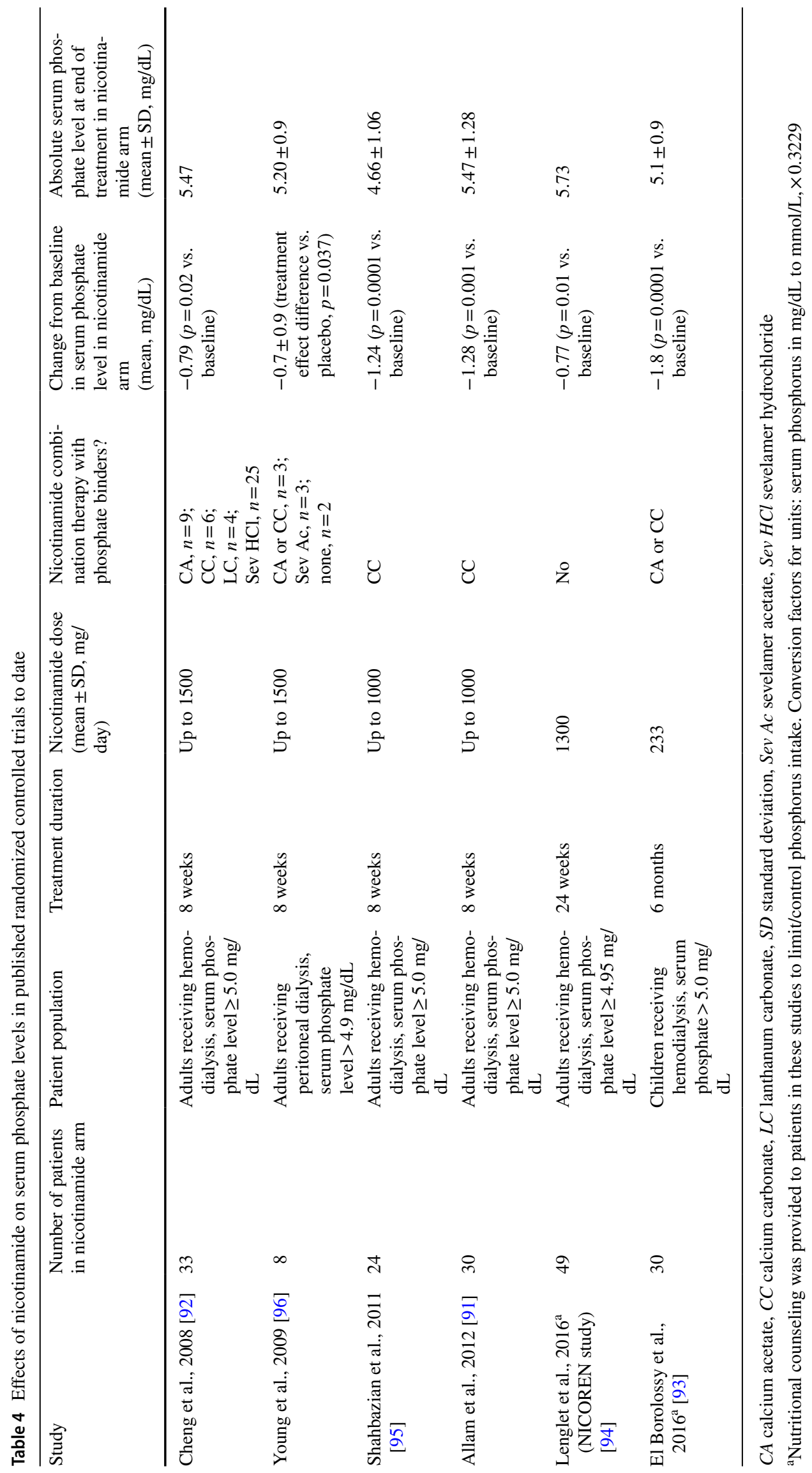


phosphate binders alone [93]. The mean serum phosphate level decreased from $6.9 \pm 1.6 \mathrm{mg} / \mathrm{dL}$ at baseline to $5.1 \pm 0.9 \mathrm{mg} / \mathrm{dL}$ at month $6(p<0.0001)$ in the group receiving nicotinamide and phosphate binders, and a nominal but statistically significant increase was observed in those receiving phosphate binders alone (baseline, $7.7 \pm 1.9 \mathrm{mg}$ / $\mathrm{dL}$; month 6, $8.1 \pm 1.4 \mathrm{mg} / \mathrm{dL} ; p<0.0001$; between-group comparison, $p=0.001$ ) [93]. In a separate prospective, randomized, double-blind, placebo-controlled crossover study, adult patients receiving hemodialysis and phosphate binders $(n=33)$ were randomized to receive add-on nicotinamide (up to $1.5 \mathrm{~g} /$ day) or add-on placebo for 8 weeks [92]. The mean serum phosphate fell significantly in the group receiving nicotinamide and phosphate binders (baseline, $6.26 \mathrm{mg} / \mathrm{dL}$; week $8,5.47 \mathrm{mg} / \mathrm{dL} ; p=0.02$ ), but no change was reported in the group receiving placebo and phosphate binders (baseline, $5.85 \mathrm{mg} / \mathrm{dL}$; week $8,5.98 \mathrm{mg} / \mathrm{dL} ; p=0.73$; betweengroup difference, $p=0.05)$. The phosphate-lowering effect of nicotinamide was most pronounced in those patients with a treatment compliance level of at least $80 \%$ [92].

\subsection{Safety/Tolerability Profile}

Nicotinamide is a metabolite of nicotinic acid. Thus, some AEs associated with nicotinic acid, such as myalgia, raised glucose concentrations, and elevated liver enzyme levels [97], should be monitored following nicotinamide administration. Nicotinic acid is licensed and is available as an extended-release formulation, ERN [97]. The ERN formulation in combination with laropiprant and/or statins (HMGCoA reductase inhibitors) has been assessed in several clinical studies in patients with cardiovascular disease [98, 99]. However, further clinical use was stopped due to lack of efficacy (in terms of reducing fatal or non-fatal cardiovascular events) $[98,99]$ and concerns over safety and tolerability (including increased risks of serious gastrointestinal, musculoskeletal, infection/infestation, bleeding event, and skin-related AEs, and disturbed glucose control/new-onset diabetes mellitus) [99-101]. A subgroup analysis of the AIM-HIGH (Atherothrombosis Intervention in Metabolic Syndrome with Low HDL/High Triglycerides: Impact on Global Health Outcomes) trial focused on the effects of ERN on mineral metabolism parameters in patients with cardiovascular disease and concomitant mild-to-moderate CKD [102]. ERN had a modest effect on serum phosphate concentrations over 3 years, with levels $0.08 \mathrm{mg} / \mathrm{dL}$ lower per year than placebo $(p<0.01)$, but no corresponding changes in FGF-23 or PTH were observed [102]. In terms of the possible implications of these findings concerning nicotinamide, two issues should be considered. First, it cannot be assumed that the tolerability profile of nicotinamide will be identical to that for nicotinic acid, as both molecules represent unique pharmacological entities. Indeed, nicotinic acid causes flushing via $\mathrm{G}$ protein-coupled 109A niacin receptor-mediated prostaglandin release; nicotinamide does not bind to this receptor [103-105]. Second, the combination of nicotinic acid plus statins may have caused drug-drug interactions that led to certain AEs, such as myopathy and rhabdomyolysis [97]. This may also be an issue when nicotinamide is used to treat hyperphosphatemia, as some patients with CKD are also prescribed statins.

According to data from published trials in patients with CKD receiving dialysis, nicotinamide was generally well tolerated. The most frequent AEs occurring with nicotinamide use were gastrointestinal disturbances (including diarrhea) [81, 91-95] and thrombocytopenia [81, 94, 95]. AEs such as flushing [91-93] and rash [91-93] were observed occasionally. In four of these studies, no patients discontinued nicotinamide treatment $[81,92,93,95]$.

The terminal nicotinamide metabolite $N$-methyl-2-pyridone-5-carboxamide (2PY) is known to accumulate in patients with CKD [106-108]. As 2PY exerts biological activity by means of inhibiting poly(ADP-ribose) polymerase (PARP-1) [107], the European Uremic Toxins (EUTox) working group classified $2 \mathrm{PY}$ as a low-molecular-weight, water-soluble, non-protein-bound uremic toxin that can be removed by dialysis $[109,110]$. PARP-1 is a nuclear enzyme involved in cellular response to DNA damage. Controversially, inhibition of PARP-1 has been shown to exert cytoprotective functions; however, excessive or long-term inhibition may be harmful owing to the impairment of DNA repair mechanisms [106, 108]. Use of PARP inhibitors for the treatment of several types of cancer was shown to induce thrombocytopenia, suggesting that this adverse drug reaction, also reported in patients with CKD receiving nicotinamide, may be linked to 2PY accumulation [108].

For example, in the NICOREN (Nicotinamide Versus Sevelamer Hydrochloride on Phosphatemia Control on Chronic Hemodialysed Patients) trial [94], thrombocytopenia was among the most common AEs, along with nausea and diarrhea. In four of the 49 patients receiving nicotinamide, platelet counts decreased to $<70 \times 10^{3} / \mu \mathrm{L}$, which resolved within 4 weeks of stopping treatment [94]. Mean platelet concentration exhibited only minor changes with nicotinamide treatment. At baseline, serum 2PY levels were similar for patients in the nicotinamide and sevelamer groups. By week 24, serum 2PY levels had increased significantly with nicotinamide and were fivefold higher than that of patients in the sevelamer group $(21,285 \pm 17,747 \mathrm{ng} / \mathrm{mL}$ vs. $3743 \pm 5497 \mathrm{ng} / \mathrm{mL}$, respectively; $p<0.001$ ) [94]. Further research is needed to understand how the accumulation of 2PY may trigger thrombocytopenia in individual patients. 


\subsection{Future Studies}

Although these trials show promising phosphate-lowering effects of nicotinamide in patients with hyperphosphatemia, they are limited by the short duration (8-24 weeks) and small participant numbers $(n=8-65$ in the nicotinamide arms). Accordingly, the 1-year, phase III COMBINE (CKD Optimal Management with Binders and Nicotinamide) study (ClinicalTrials.gov identifier: NCT02258074) will investigate the effects on serum phosphate levels of nicotinamide (750 mg twice daily) in combination with lanthanum carbonate (1000 mg three times daily) in patients with CKD stages 3-4 $(n=205)$. The primary endpoint will be the change in serum phosphate and FGF-23 levels from baseline to month 12 [111]. In addition, the 1-year NOPHOS (Nicotinamide As Add-on Therapy compared to Placebo in Dialysis-Dependent Patients with Hyperphosphatemia; EudraCT Number: 2013-000488-95) phase III study in 700 patients will soon provide important placebo-controlled data on the therapeutic add-on effect of modified-release nicotinamide in combination with phosphate binders. The primary endpoint of this trial will be the change in serum phosphate level from baseline to week 12 , with secondary endpoints such as serum phosphate concentrations, serum calcium concentrations, intact parathyroid hormone, high- and lowdensity lipoproteins, and triglycerides assessed over 1 year [112]. The 8-week, phase II DONATO (DOse-finding trial of NicotinAmide in dialysis-dependenT patients with hyperphOsphatemia; ClinicalTrials.gov identifier: NCT01200784) study compared the effects of nicotinamide modified release $(250,500,750$, and $1000 \mathrm{mg} /$ day) with nicotinamide immediate release (1000 mg/day; $n=252)$ [113], but results have not yet been reported.

In summary, both dietary phosphate restriction and phosphate-binder therapy limit gastrointestinal uptake of phosphate mainly by passive paracellular diffusion, but might cause an undesirable maladaptive increase in phosphate uptake by promoting active phosphate transport through increased expression of gastrointestinal NaPi2b. By blocking $\mathrm{NaPi} 2 \mathrm{~b}$ cotransporters in the gut, nicotinamide may overcome the limitations of these two interventions while potentially increasing their efficacy and reducing phosphatebinder dose and pill burden.

\section{Conclusion}

Despite current treatments, many patients with dialysisdependent CKD do not achieve target serum phosphate levels. Additional therapeutic strategies to those currently used are needed to manage hyperphosphatemia. Potential alternative strategies include the NHE3 ion-exchange inhibitor tenapanor and the $\mathrm{NaPi} 2 \mathrm{~b}$ cotransporter inhibitor nicotinamide, both of which have mechanisms of action that actively inhibit gastrointestinal phosphate absorption. Preliminary clinical evidence suggests that both agents lower serum phosphate levels and overall have an acceptable tolerability profile in patients with CKD, but more long-term safety data are needed. Although a large body of clinical data documents long-term use of nicotinamide for the treatment of different conditions, the clinical implications of 2PY accumulation in patients with CKD should be the subject of further research.

Clinically relevant outcomes are unknown for tenapanor as well as nicotinamide and need to be examined in clinical trials. If such trials show beneficial effects, drugs that target active gastrointestinal phosphate transport combined with phosphate-binder therapy could optimize the therapeutic effects of both treatments and enhance the effectiveness of dietary phosphate restriction. As optimal phosphate control in advanced CKD remains an unmet need, these developments are promising avenues that may ultimately lead to improved clinical outcomes for patients with CKD.

Acknowledgments Medical writing and editorial support were provided by Dr Ian M. Williams of Oxford PharmaGenesis Ltd (Oxford, UK). Open access fees and medical writing and editorial support were funded by Medice Arzneimittel Pütter GmbH \& Co KG.

\section{Compliance with Ethical Standards}

Funding Medice Arzneimittel Pütter GmbH \& Co KG funded medical writing/editorial support for preparation of the manuscript. The final decision to submit was that of the authors.

Conflict of interest Denis Fouque has received lecture fees from Fresenius Medical Care, Fresenius Kabi, Sanofi, Amgen, and Vifor; travel support from Fresenius Kabi and Vifor; and consulting fees from Fresenius Kabi, Sanofi, and Vifor. Marc Vervloet has received lecture or consulting fees from B Braun, Amgen, Baxter, Otsuka, Medice, and VFMCRP. Markus Ketteler has received lecture or consulting fees from Amgen, Bayer (Japan), BMS, FMC, Kissei, Kyowa Kirin, Medice, Pfizer, Sanifit, Sanofi, Shire, and Vifor Fresenius Medical Care Renal Pharma.

Open Access This article is distributed under the terms of the Creative Commons Attribution-NonCommercial 4.0 International License (http://creativecommons.org/licenses/by-nc/4.0/), which permits any noncommercial use, distribution, and reproduction in any medium, provided you give appropriate credit to the original author(s) and the source, provide a link to the Creative Commons license, and indicate if changes were made.

\section{References}

1. Hruska KA, Mathew S, Lund R, Qiu P, Pratt R. Hyperphosphatemia of chronic kidney disease. Kidney Int. 2008;74(2):148-57. 
2. Tonelli M, Pannu N, Manns B. Oral phosphate binders in patients with kidney failure. N Engl J Med. 2010;362(14):1312-24.

3. Sabbagh Y, Giral H, Caldas Y, Levi M, Schiavi SC. Intestinal phosphate transport. Adv Chronic Kidney Dis. 2011;18(2):85-90.

4. Marks J, Debnam ES, Unwin RJ. Phosphate homeostasis and the renal-gastrointestinal axis. Am J Physiol Renal Physiol. 2010;299(2):F285-96.

5. Davis GR, Zerwekh JE, Parker TF, Krejs GJ, Pak CY, Fordtran JS. Absorption of phosphate in the jejunum of patients with chronic renal failure before and after correction of vitamin D deficiency. Gastroenterology. 1983;85(4):908-16.

6. Forster IC, Hernando N, Biber J, Murer H. Phosphate transporters of the SLC20 and SLC34 families. Mol Aspects Med. 2013;34(2-3):386-95.

7. Giral H, Caldas Y, Sutherland E, Wilson P, Breusegem S, Barry $\mathrm{N}$, et al. Regulation of rat intestinal Na-dependent phosphate transporters by dietary phosphate. Am J Physiol Renal Physiol. 2009;297(5):F1466-75.

8. Villa-Bellosta R, Ravera S, Sorribas V, Stange G, Levi M, Murer $\mathrm{H}$, et al. The $\mathrm{Na}^{+}-\mathrm{Pi}$ cotransporter PiT-2 (SLC20A2) is expressed in the apical membrane of rat renal proximal tubules and regulated by dietary Pi. Am J Physiol Renal Physiol. 2009;296(4):F691-9.

9. Sabbagh Y, O'Brien SP, Song W, Boulanger JH, Stockmann $\mathrm{A}$, Arbeeny $\mathrm{C}$, et al. Intestinal npt2b plays a major role in phosphate absorption and homeostasis. J Am Soc Nephrol. 2009;20(11):2348-58.

10. Schiavi SC, Tang W, Bracken C, O'Brien SP, Song W, Boulanger $\mathrm{J}$, et al. Npt2b deletion attenuates hyperphosphatemia associated with CKD. J Am Soc Nephrol. 2012;23(10):1691-700.

11. Radanovic T, Wagner CA, Murer H, Biber J. Regulation of intestinal phosphate transport. I. Segmental expression and adaptation to low-P(i) diet of the type IIb $\mathrm{Na}(+)-\mathrm{P}(\mathrm{i})$ cotransporter in mouse small intestine. Am J Physiol Gastrointest Liver Physiol. 2005;288(3):G496-500.

12. Hattenhauer O, Traebert M, Murer H, Biber J. Regulation of small intestinal Na-P(i) type IIb cotransporter by dietary phosphate intake. Am J Physiol. 1999;277(4 Pt 1):G756-62.

13. Huber K, Walter C, Schroder B, Breves G. Phosphate transport in the duodenum and jejunum of goats and its adaptation by dietary phosphate and calcium. Am J Physiol Regul Integr Comp Physiol. 2002;283(2):R296-302.

14. Saddoris KL, Fleet JC, Radcliffe JS. Sodium-dependent phosphate uptake in the jejunum is post-transcriptionally regulated in pigs fed a low-phosphorus diet and is independent of dietary calcium concentration. J Nutr. 2010;140(4):731-6.

15. Segawa $H$, Kaneko I, Yamanaka $S$, Ito $M$, Kuwahata M, Inoue $Y$, et al. Intestinal Na-P(i) cotransporter adaptation to dietary P(i) content in vitamin D receptor null mice. Am J Physiol Renal Physiol. 2004;287(1):F39-47.

16. Capuano P, Radanovic T, Wagner CA, Bacic D, Kato S, Uchiyama $\mathrm{Y}$, et al. Intestinal and renal adaptation to a low-Pi diet of type II NaPi cotransporters in vitamin D receptor- and 1alphaOHase-deficient mice. Am J Physiol Cell Physiol. 2005;288(2):C429-34.

17. Nishida Y, Taketani Y, Yamanaka-Okumura H, Imamura F, Taniguchi A, Sato T, et al. Acute effect of oral phosphate loading on serum fibroblast growth factor 23 levels in healthy men. Kidney Int. 2006;70(12):2141-7. https://doi.org/10.1038/sj.ki.5002000.

18. Shuto E, Taketani Y, Tanaka R, Harada N, Isshiki M, Sato M, et al. Dietary phosphorus acutely impairs endothelial function. J Am Soc Nephrol. 2009;20(7):1504-12. https://doi.org/10.1681/ ASN.2008101106.

19. Miyamoto K, Ito M, Kuwahata M, Kato S, Segawa H. Inhibition of intestinal sodium-dependent inorganic phosphate transport by fibroblast growth factor 23. Ther Apher Dial. 2005;9(4):331-5.
20. Xu H, Bai L, Collins JF, Ghishan FK. Age-dependent regulation of rat intestinal type IIb sodium-phosphate cotransporter by $1,25-(\mathrm{OH})(2)$ vitamin $\mathrm{D}(3)$. Am J Physiol Cell Physiol. 2002;282(3):C487-93.

21. Razzaque MS. Phosphate toxicity: new insights into an old problem. Clin Sci (Lond). 2011;120(3):91-7.

22. Corut A, Senyigit A, Ugur SA, Altin S, Ozcelik U, Calisir H, et al. Mutations in SLC34A2 cause pulmonary alveolar microlithiasis and are possibly associated with testicular microlithiasis. Am J Hum Genet. 2006;79(4):650-6.

23. Levin A, Bakris GL, Molitch M, Smulders M, Tian J, Williams LA, et al. Prevalence of abnormal serum vitamin D, PTH, calcium, and phosphorus in patients with chronic kidney disease: results of the study to evaluate early kidney disease. Kidney Int. 2007;71(1):31-8.

24. National Kidney Foundation Kidney Disease Outcomes Quality Initiative (NKF KDOQI). Clinical practice guidelines for chronic kidney disease: evaluation, classification, and stratification. Part 6. Association of level of GFR with complications in adults. New York: National Kidney Foundation, Inc.; 2002.

25. Isakova T, Wahl P, Vargas GS, Gutierrez OM, Scialla J, Xie H, et al. Fibroblast growth factor 23 is elevated before parathyroid hormone and phosphate in chronic kidney disease. Kidney Int. 2011;79(12):1370-8.

26. Block GA, Hulbert-Shearon TE, Levin NW, Port FK. Association of serum phosphorus and calcium $\mathrm{x}$ phosphate product with mortality risk in chronic hemodialysis patients: a national study. Am J Kidney Dis. 1998;31(4):607-17.

27. Block GA, Klassen PS, Lazarus JM, Ofsthun N, Lowrie EG, Chertow GM. Mineral metabolism, mortality, and morbidity in maintenance hemodialysis. J Am Soc Nephrol. 2004;15(8):2208-18.

28. Kalantar-Zadeh K, Kuwae N, Regidor DL, Kovesdy CP, Kilpatrick RD, Shinaberger CS, et al. Survival predictability of timevarying indicators of bone disease in maintenance hemodialysis patients. Kidney Int. 2006;70(4):771-80.

29. Kestenbaum B, Sampson JN, Rudser KD, Patterson DJ, Seliger SL, Young B, et al. Serum phosphate levels and mortality risk among people with chronic kidney disease. J Am Soc Nephrol. 2005;16(2):520-8.

30. Floege J, Kim J, Ireland E, Chazot C, Drueke T, de Francisco A, et al. Serum iPTH, calcium and phosphate, and the risk of mortality in a European haemodialysis population. Nephrol Dial Transpl. 2011;26(6):1948-55.

31. Fouque D, Roth H, Pelletier S, London GM, Hannedouche T, Jean $\mathrm{G}$, et al. Control of mineral metabolism and bone disease in haemodialysis patients: which optimal targets? Nephrol Dial Transpl. 2013;28(2):360-7.

32. Noordzij M, Korevaar JC, Boeschoten EW, Dekker FW, Bos WJ, Krediet RT. The Kidney Disease Outcomes Quality Initiative (K/DOQI) guideline for bone metabolism and disease in CKD: association with mortality in dialysis patients. Am J Kidney Dis. 2005;46(5):925-32.

33. Phelan PJ, O'Kelly P, Walshe JJ, Conlon PJ. The importance of serum albumin and phosphorous as predictors of mortality in ESRD patients. Ren Fail. 2008;30(4):423-9.

34. Fouque D, Roth H, Darne B, Jean-Bouchet L, Daugas E, Drueke TB, et al. Achievement of Kidney Disease: Improving Global Outcomes mineral and bone targets between 2010 and 2014 in incident dialysis patients in France: the Photo-Graphe3 study. Clin Kidney J. 2018;11(1):73-9.

35. Djukanovic L, Dimkovic N, Marinkovic J, Djuric Z, Knezevic $\mathrm{V}$, Lazarevic T, et al. Association between hemodialysis patient outcomes and compliance with KDOQI and KDIGO targets for mineral and bone metabolism. Nephron. 2016;132(3):168-74. 
36. Fernandez-Martin JL, Martinez-Camblor P, Dionisi MP, Floege J, Ketteler M, London G, et al. Improvement of mineral and bone metabolism markers is associated with better survival in haemodialysis patients: the COSMOS study. Nephrol Dial Transplant. 2015;30(9):1542-51.

37. Soohoo M, Feng M, Obi Y, Streja E, Rhee CM, Lau WL, et al. Changes in markers of mineral and bone disorders and mortality in incident hemodialysis patients. Am J Nephrol. 2016;43(2):8596. https://doi.org/10.1159/000444890.

38. Ix JH, De Boer IH, Peralta CA, Adeney KL, Duprez DA, Jenny NS, et al. Serum phosphorus concentrations and arterial stiffness among individuals with normal kidney function to moderate kidney disease in MESA. Clin J Am Soc Nephrol. 2009;4(3):609-15.

39. Foley RN, Collins AJ, Herzog CA, Ishani A, Kalra PA. Serum phosphorus levels associate with coronary atherosclerosis in young adults. J Am Soc Nephrol. 2009;20(2):397-404.

40. Adeney KL, Siscovick DS, Ix JH, Seliger SL, Shlipak MG, Jenny NS, et al. Association of serum phosphate with vascular and valvular calcification in moderate CKD. J Am Soc Nephrol. 2009;20(2):381-7.

41. KDIGO CKD-MBD Work Group. Clinical practice guideline for the diagnosis, evaluation, prevention and treatment of chronic kidney disease-mineral and bone disorder (CKD-MBD). Kidney Int. 2009;76(suppl 113):S1-S130.

42. KDIGO CKD-MBD Update Work Group. KDIGO 2017 clinical practice guideline update for the diagnosis, evaluation, prevention, and treatment of chronic kidney disease-mineral and bone disorder (CKD-MBD). Kidney Int Suppl. 2017;2017(7):1-59.

43. Arenas MD, Alvarez-Ude F, Gil MT, Soriano A, Egea JJ, Millan I, et al. Application of NKF-K/DOQI Clinical Practice Guidelines for Bone Metabolism and Disease: changes of clinical practices and their effects on outcomes and quality standards in three haemodialysis units. Nephrol Dial Transplant. 2006;21(6): 1663-8.

44. Craver L, Marco MP, Martinez I, Rue M, Borras M, Martin ML, et al. Mineral metabolism parameters throughout chronic kidney disease stages 1-5-achievement of K/DOQI target ranges. Nephrol Dial Transplant. 2007;22(4):1171-6.

45. Lamb EJ, Hodsman A, van Schalkwyk D, Ansell D, Warwick G. Serum calcium, phosphate, parathyroid hormone, albumin, aluminium and cholesterol achievement on replacement therapy (chapter 9). Nephrol Dial Transplant. 2007;22 Suppl 7:vii105-18.

46. Lebner AC, Beard KM, Soroka SD, Cournoyer SH, Da Roza GA, Geary DF, et al. Interprovincial differences in the achievement of K/DOQI targets of mineral metabolism in Canada. Nephrol Dial Transplant. 2011;26(1):156-63.

47. Moe SM, Chertow GM, Coburn JW, Quarles LD, Goodman WG, Block GA, et al. Achieving NKF-K/DOQI bone metabolism and disease treatment goals with cinacalcet $\mathrm{HCl}$. Kidney Int. 2005;67(2):760-71.

48. Palomares I, Ramos R, Martin-Malo A, Merello JI, Praga M, Luno J, et al. Compliance with mineral metabolism targets in haemodialysis patients: moving backwards? Blood Purif. 2013;36(2):122-31.

49. Pronai W, Rosenkranz AR, Bock A, Klauser-Braun R, Jager C, Pendl G, et al. Management of secondary hyperparathyroidism: practice patterns and outcomes of cinacalcet treatment with or without active vitamin D in Austria and Switzerlandthe observational TRANSIT Study. Wien Klin Wochenschr. 2017;129(9-10):317-28.

50. Cannata-Andia JB, Martin KJ. The challenge of controlling phosphorus in chronic kidney disease. Nephrol Dial Transpl. 2016;31(4):541-7.

51. Ketteler M, Block GA, Evenepoel P, Fukagawa M, Herzog CA, McCann L, et al. Executive summary of the 2017 KDIGO
Chronic Kidney Disease-Mineral and Bone Disorder (CKDMBD) Guideline Update: what's changed and why it matters. Kidney Int. 2017;92(1):26-36.

52. Isakova T, Nickolas TL, Denburg M, Yarlagadda S, Weiner DE, Gutierrez OM, et al. KDOQI US commentary on the 2017 KDIGO clinical practice guideline update for the diagnosis, evaluation, prevention, and treatment of chronic kidney diseasemineral and bone disorder (CKD-MBD). Am J Kidney Dis. 2017;70(6):737-51.

53. K/DOQI. K/DOQI clinical practice guidelines for bone metabolism and disease in chronic kidney disease. Am J Kidney Dis. 2003;42(Suppl. 3):S1-201.

54. Shinaberger CS, Greenland S, Kopple JD, Van Wyck D, Mehrotra R, Kovesdy CP, et al. Is controlling phosphorus by decreasing dietary protein intake beneficial or harmful in persons with chronic kidney disease? Am J Clin Nutr. 2008;88(6):1511-8. https://doi.org/10.3945/ajen.2008.26665.

55. Cannata-Andia JB, Fernandez-Martin JL, Locatelli F, London G, Gorriz JL, Floege J, et al. Use of phosphate-binding agents is associated with a lower risk of mortality. Kidney Int. 2013;84(5):998-1008.

56. Isakova T, Gutierrez OM, Chang Y, Shah A, Tamez H, Smith K, et al. Phosphorus binders and survival on hemodialysis. J Am Soc Nephrol. 2009;20(2):388-96.

57. Lopes AA, Tong L, Thumma J, Li Y, Fuller DS, Morgenstern $\mathrm{H}$, et al. Phosphate binder use and mortality among hemodialysis patients in the Dialysis Outcomes and Practice Patterns Study (DOPPS): evaluation of possible confounding by nutritional status. Am J Kidney Dis. 2012;60(1):90-101. https://doi. org/10.1053/j.ajkd.2011.12.025.

58. Wald R, Rabbat CG, Girard L, Garg AX, Tennankore K, Tyrwhitt $\mathrm{J}$, et al. Two phosphAte taRGets in End-stage renal disease Trial (TARGET): a randomized controlled trial. Clin J Am Soc Nephrol. 2017;12(6):965-73. https://doi.org/10.2215/CJN.10941016.

59. Di Iorio B, Molony D, Bell C, Cucciniello E, Bellizzi V, Russo $\mathrm{D}$, et al. Sevelamer versus calcium carbonate in incident hemodialysis patients: results of an open-label 24-month randomized clinical trial. Am J Kidney Dis. 2013;62(4):771-8.

60. Patel L, Bernard LM, Elder GJ. Sevelamer versus calcium-based binders for treatment of hyperphosphatemia in CKD: a metaanalysis of randomized controlled trials. Clin J Am Soc Nephrol. 2016;11(2):232-44.

61. Palmer SC, Gardner S, Tonelli M, Mavridis D, Johnson DW, Craig JC, et al. Phosphate-binding agents in adults with CKD: a network meta-analysis of randomized trials. Am J Kidney Dis. 2016;68(5):691-702.

62. Airy M, Winkelmayer WC, Navaneethan SD. Phosphate binders: the evidence gap persists. Am J Kidney Dis. 2016;68(5):667-70.

63. Hiremath S, Akbari A. Calcium-based phosphate binders and chronic kidney disease. Lancet. 2014;383(9913):216. https://doi. org/10.1016/S0140-6736(14)60070-2.

64. Fernandez-Martin JL, Carrero JJ, Benedik M, Bos WJ, Covic A, Ferreira A, et al. COSMOS: the dialysis scenario of CKD-MBD in Europe. Nephrol Dial Transpl. 2013;28(7):1922-35.

65. Frazao JM, Messa P, Mellotte GJ, Geiger H, Hagen EC, Quarles $\mathrm{LD}$, et al. Cinacalcet reduces plasma intact parathyroid hormone, serum phosphate and calcium levels in patients with secondary hyperparathyroidism irrespective of its severity. Clin Nephrol. 2011;76(3):233-43.

66. Zitt E, Fouque D, Jacobson SH, Malberti F, Ryba M, Urena P, et al. Serum phosphorus reduction in dialysis patients treated with cinacalcet for secondary hyperparathyroidism results mainly from parathyroid hormone reduction. Clin Kidney J. 2013;6(3):287-94.

67. Hedgeman E, Lipworth L, Lowe K, Saran R, Do T, Fryzek J. International burden of chronic kidney disease and secondary 
hyperparathyroidism: a systematic review of the literature and available data. Int J Nephrol. 2015;2015:184321.

68. Labonte ED, Carreras CW, Leadbetter MR, Kozuka K, Kohler J, Koo-McCoy S, et al. Gastrointestinal inhibition of sodiumhydrogen exchanger 3 reduces phosphorus absorption and protects against vascular calcification in CKD. J Am Soc Nephrol. 2015;26(5):1138-49.

69. Spencer AG, Labonte ED, Rosenbaum DP, Plato CF, Carreras CW, Leadbetter MR, et al. Intestinal inhibition of the $\mathrm{Na}^{+}$/ $\mathrm{H}^{+}$exchanger 3 prevents cardiorenal damage in rats and inhibits $\mathrm{Na}^{+}$uptake in humans. Sci Transl Med. 2014;6(227):227ra36.

70. Block GA, Rosenbaum DP, Leonsson-Zachrisson M, Stefansson BV, Ryden-Bergsten T, Greasley PJ, et al. Effect of tenapanor on interdialytic weight gain in patients on hemodialysis. Clin J Am Soc Nephrol. 2016;11(9):1597-605.

71. Johansson S, Rosenbaum DP, Knutsson M, Leonsson-Zachrisson M. A phase 1 study of the safety, tolerability, pharmacodynamics, and pharmacokinetics of tenapanor in healthy Japanese volunteers. Clin Exp Nephrol. 2017;21(3):407-16.

72. Johansson S, Leonsson-Zachrisson M, Knutsson M, Spencer AG, Labonte ED, Deshpande D, et al. Preclinical and healthy volunteer studies of potential drug-drug interactions between tenapanor and phosphate binders. Clin Pharmacol Drug Dev. 2017;6(5):448-56.

73. Johansson SA, Knutsson M, Leonsson-Zachrisson M, Rosenbaum DP. Effect of food intake on the pharmacodynamics of tenapanor: a phase 1 study. Clin Pharmacol Drug Dev. 2017;6(5):457-65.

74. Block GA, Rosenbaum DP, Yan A, Greasley PJ, Chertow GM, Wolf $\mathrm{M}$. The effects of tenapanor on serum fibroblast growth factor 23 in patients receiving hemodialysis with hyperphosphatemia. Nephrol Dial Transplant. 2018. https://doi. org/10.1093/ndt/gfy061.

75. King A. Inhibition of sodium/hydrogen exchanger 3 in the gastrointestinal tract by tenapanor reduces paracellular phosphate permeability. Sci Trans Med (in press).

76. Block GA, Rosenbaum DP, Leonsson-Zachrisson M, Astrand M, Johansson S, Knutsson M, et al. Effect of tenapanor on serum phosphate in patients receiving hemodialysis. J Am Soc Nephrol. 2017;28(6): 1933-42.

77. Munetomo E, Takahashi T, Yamamoto K, Abe T, Tomoike H, Kajiyama $\mathrm{H}$, et al. A novel, selective, and non-systemic $\mathrm{Na}^{+}$/ $\mathrm{H}^{+}$exchanger 3 inhibitor, TP0469711, potently enhances phosphate excretion with a favorable gastrointestinal tolerability in rats [abstract no. TH-PO1047]. J Am Soc Nephrol. 2017;28:373.

78. Taniguchi K, Terai K, Terada Y, Tomura Y. Novel NaPi-IIb inhibitor ASP3325 inhibits phosphate absorption in intestine and reduces plasma phosphorus level in rats with renal failure [FR-PO936]. J Am Soc Nephrol. 2015;26:382A.

79. Larsson TE, Kameoka C, Nakajo I, Taniuchi Y, Yoshida S, Akizawa T, et al. NPT-IIb inhibition does not improve hyperphosphatemia in CKD. Kidney Int Rep. 2018;3:73-80.

80. Sampathkumar K. Niacin and analogs for phosphate control in dialysis-perspective from a developing country. Int Urol Nephrol. 2009;41(4):913-8.

81. Takahashi Y, Tanaka A, Nakamura T, Fukuwatari T, Shibata K, Shimada N, et al. Nicotinamide suppresses hyperphosphatemia in hemodialysis patients. Kidney Int. 2004;65(3):1099-104.

82. Sampathkumar K, Selvam M, Sooraj YS, Gowthaman S, Ajeshkumar RN. Extended release nicotinic acid-a novel oral agent for phosphate control. Int Urol Nephrol. 2006;38(1):171-4. https ://doi.org/10.1007/s11255-006-0001-x.

83. Maccubbin D, Tipping D, Kuznetsova O, Hanlon WA, Bostom AG. Hypophosphatemic effect of niacin in patients without renal failure: a randomized trial. Clin J Am Soc Nephrol. 2010;5(4):582-9.

84. Eto N, Miyata Y, Ohno H, Yamashita T. Nicotinamide prevents the development of hyperphosphataemia by suppressing intestinal sodium-dependent phosphate transporter in rats with adenineinduced renal failure. Nephrol Dial Transpl. 2005;20(7):1378-84.

85. Katai K, Tanaka H, Tatsumi S, Fukunaga Y, Genjida K, Morita $\mathrm{K}$, et al. Nicotinamide inhibits sodium-dependent phosphate cotransport activity in rat small intestine. Nephrol Dial Transpl. 1999;14(5):1195-201.

86. Kempson SA, Colon-Otero G, Ou SY, Turner ST, Dousa TP. Possible role of nicotinamide adenine dinucleotide as an intracellular regulator of renal transport of phosphate in the rat. J Clin Invest. 1981;67(5):1347-60.

87. Berndt TJ, Pfeifer JD, Knox FG, Kempson SA, Dousa TP. Nicotinamide restores phosphaturic effect of PTH and calcitonin in phosphate deprivation. Am J Physiol. 1982;242(5):F447-52. https://doi.org/10.1152/ajprenal.1982.242.5.F447.

88. Haramati A, Knox FG. Tubular capacity of phosphate transport in phosphate-deprived rats: effects of nicotinamide and PTH. Am J Physiol. 1983;244(2):F178-84. https://doi.org/10.1152/ajpre nal.1983.244.2.F178.

89. Wu KI, Bacon RA, Al-Mahrouq HA, Kempson SA. Nicotinamide as a rapid-acting inhibitor of renal brush-border phosphate transport. Am J Physiol. 1988;255(1 Pt 2):F15-21. https://doi. org/10.1152/ajprenal.1988.255.1.F15.

90. Nomura K, Tatsumi S, Miyagawa A, Shiozaki Y, Sasaki S, Kaneko I, et al. Hepatectomy-related hypophosphatemia: a novel phosphaturic factor in the liver-kidney axis. J Am Soc Nephrol. 2014;25(4):761-72. https://doi.org/10.1681/ASN.2013060569.

91. Allam S, El-Hamamsy M, El Sharkawy M. The effect of coadminstration of nicotinamide and calcium-based phosphate binder on hyperphosphatemia in patients undergoing hemodialysis. Adv Nat Sci. 2012;5:1-9.

92. Cheng SC, Young DO, Huang Y, Delmez JA, Coyne DW. A randomized, double-blind, placebo-controlled trial of niacinamide for reduction of phosphorus in hemodialysis patients. Clin J Am Soc Nephrol. 2008;3(4):1131-8.

93. El Borolossy R, El Wakeel LM, El Hakim I, Sabri N. Efficacy and safety of nicotinamide in the management of hyperphosphatemia in pediatric patients on regular hemodialysis. Pediatr Nephrol. 2016;31(2):289-96.

94. Lenglet A, Liabeuf S, El Esper N, Brisset S, Mansour J, LemaireHurtel AS, et al. Efficacy and safety of nicotinamide in haemodialysis patients: the NICOREN study. Nephrol Dial Transpl. 2016;32(5):870-9.

95. Shahbazian H, Zafar Mohtashami A, Ghorbani A, Abbaspour MR, Belladi Musavi SS, Hayati F, et al. Oral nicotinamide reduces serum phosphorus, increases HDL, and induces thrombocytopenia in hemodialysis patients: a double-blind randomized clinical trial. Nefrologia. 2011;31(1):58-65.

96. Young DO, Cheng SC, Delmez JA, Coyne DW. The effect of oral niacinamide on plasma phosphorus levels in peritoneal dialysis patients. Perit Dial Int. 2009;29(5):562-7.

97. AbbVie. NIASPAN Prescribing Information. 2015. http://www. rxabbvie.com/pdf/niaspan.pdf. Accessed 15 Mar 2017.

98. Investigators Aim-High, Boden WE, Probstfield JL, Anderson T, Chaitman BR, Desvignes-Nickens $P$, et al. Niacin in patients with low HDL cholesterol levels receiving intensive statin therapy. N Engl J Med. 2011;365(24):2255-67.

99. HPS Thrive Collaborative Group, Landray MJ, Haynes R, Hopewell JC, Parish S, Aung T et al. Effects of extended-release niacin with laropiprant in high-risk patients. N Engl J Med. 2014;371(3):203-12. 
100. Anderson TJ, Boden WE, Desvigne-Nickens P, Fleg JL, Kashyap ML, McBride R, et al. Safety profile of extended-release niacin in the AIM-HIGH trial. N Engl J Med. 2014;371(3):288-90.

101. HPS Thrive Collaborative Group. HPS2-THRIVE randomized placebo-controlled trial in 25673 high-risk patients of ER niacin/laropiprant: trial design, pre-specified muscle and liver outcomes, and reasons for stopping study treatment. Eur Heart J. 2013;34(17):1279-91.

102. Malhotra R, Katz R, Hoofnagle A, Bostom A, Rifkin DE, McBride $\mathrm{R}$, et al. The effect of extended release niacin on markers of mineral metabolism in CKD. Clin J Am Soc Nephrol. 2018;13(1):36-44.

103. Kamanna VS, Kashyap ML. Mechanism of action of niacin. Am J Cardiol. 2008;101(8A):20B-6B.

104. Bodor ET, Offermanns S. Nicotinic acid: an old drug with a promising future. Br J Pharmacol. 2008;153(Suppl 1):S68-75.

105. Drueke TB, Massy ZA. Lowering expectations with niacin treatment for CKD-MBD. Clin J Am Soc Nephrol. 2018;13(1):6-8.

106. Slominska EM, Smolenski RT, Szolkiewicz M, Leaver N, Rutkowski B, Simmonds HA, et al. Accumulation of plasma $\mathrm{N}$-methyl-2-pyridone-5-carboxamide in patients with chronic renal failure. Mol Cell Biochem. 2002;231(1-2):83-8.

107. Rutkowski B, Slominska E, Szolkiewicz M, Smolenski RT, Striley C, Rutkowski P, et al. N-methyl-2-pyridone-5-carboxamide: a novel uremic toxin? Kidney Int Suppl. 2003;84:S19-21.

108. Lenglet A, Liabeuf S, Bodeau S, Louvet L, Mary A, Boullier A, et al. N-methyl-2-pyridone-5-carboxamide (2PY)-major metabolite of nicotinamide: an update on an old uremic toxin. Toxins (Basel). 2016;8(11):E339.

109. Vanholder R, De Smet R, Glorieux G, Argiles A, Baurmeister $\mathrm{U}$, Brunet $\mathrm{P}$, et al. Review on uremic toxins: classification, concentration, and interindividual variability. Kidney Int. 2003;63(5):1934-43. https://doi.org/10.104 6/j.1523-1755.2003.00924.x.

110. Vanholder R, Van Laecke S, Glorieux G. What is new in uremic toxicity? Pediatr Nephrol. 2008;23(8):1211-21. https://doi. org/10.1007/s00467-008-0762-9.
111. NCT02258074. The CKD Optimal Management with BInders and NicotinamidE (COMBINE) study. https://clinicaltrials.gov/ ct2/show/NCT02258074. Accessed 4 Apr 2017.

112. EudraCT 2013-000488-95. The NOPHOS trial. Efficacy and tolerability of nicotinamide as add-on therapy compared to placebo in dialysis-dependent patients with hyperphosphatemia. https:// www.clinicaltrialsregister.eu/ctr-search/trial/2013-000488-95/ AT. Accessed 4 Apr 2017.

113. NCT01200784. The DONATO study. Nicotinamide in hemodialysis patients with hyperphosphatemia. https://clinicaltrials.gov/ ct2/show/NCT01200784. Accessed 4 Apr 2017.

114. Reinke CM, Breitkreutz J, Leuenberger H. Aluminium in over-the-counter drugs: risks outweigh benefits? Drug Saf. 2003;26(14):1011-25.

115. Rizk R, Hiligsmann M, Karavetian M, Evers SM. Economic evaluations of interventions to manage hyperphosphataemia in adult haemodialysis patients: a systematic review. Nephrology (Carlton). 2016;21(3):178-87.

116. Fissell RB, Karaboyas A, Bieber BA, Sen A, Li Y, Lopes AA, et al. Phosphate binder pill burden, patient-reported non-adherence, and mineral bone disorder markers: findings from the DOPPS. Hemodial Int. 20116;20(1):38-49.

117. Chiu YW, Teitelbaum I, Misra M, de Leon EM, Adzize T, Mehrotra R. Pill burden, adherence, hyperphosphatemia, and quality of life in maintenance dialysis patients. Clin J Am Soc Nephrol. 2009;4(6):1089-96.

118. Arenas MD, Malek T, Gil MT, Moledous A, Alvarez-Ude F, Reig-Ferrer A. Challenge of phosphorus control in hemodialysis patients: a problem of adherence? J Nephrol. 2010;23(5):525-34.

119. Arenas MD, Malek T, Alvarez-Ude F, Gil MT, Moledous A, Reig-Ferrer A. Phosphorus binders: preferences of patients on haemodialysis and its impact on treatment compliance and phosphorus control [in Spanish]. Nefrologia. 2010;30(5):522-30.

120. Baia LC, Heilberg IP, Navis G, de Borst MH, investigators N. Phosphate and FGF-23 homeostasis after kidney transplantation. Nat Rev Nephrol. 2015;11(11):656-66. 